\title{
Tracking cognitive processes with functional MRI mental chronometry
}

Citation for published version (APA):

Formisano, E., \& Goebel, R. (2003). Tracking cognitive processes with functional MRI mental chronometry. Current Opinion in Neurobiology, 13(2), 174-181. https://doi.org/10.1016/S0959$4388(03) 00044-8$

Document status and date:

Published: 01/01/2003

DOI:

10.1016/S0959-4388(03)00044-8

Document Version:

Publisher's PDF, also known as Version of record

Document license:

Taverne

Please check the document version of this publication:

- A submitted manuscript is the version of the article upon submission and before peer-review. There can be important differences between the submitted version and the official published version of record.

People interested in the research are advised to contact the author for the final version of the publication, or visit the DOI to the publisher's website.

- The final author version and the galley proof are versions of the publication after peer review.

- The final published version features the final layout of the paper including the volume, issue and page numbers.

Link to publication

\footnotetext{
General rights rights.

- You may freely distribute the URL identifying the publication in the public portal. please follow below link for the End User Agreement:

www.umlib.nl/taverne-license

Take down policy

If you believe that this document breaches copyright please contact us at:

repository@maastrichtuniversity.nl

providing details and we will investigate your claim.
}

Copyright and moral rights for the publications made accessible in the public portal are retained by the authors and/or other copyright owners and it is a condition of accessing publications that users recognise and abide by the legal requirements associated with these

- Users may download and print one copy of any publication from the public portal for the purpose of private study or research.

- You may not further distribute the material or use it for any profit-making activity or commercial gain

If the publication is distributed under the terms of Article $25 \mathrm{fa}$ of the Dutch Copyright Act, indicated by the "Taverne" license above, 


\section{Tracking cognitive processes with functional MRI mental chronometry Elia Formisano* and Rainer Goebel ${ }^{\dagger}$}

Functional magnetic resonance imaging (fMRI) is used widely to determine the spatial layout of brain activation associated with specific cognitive tasks at a spatial scale of millimeters. Recent methodological improvements have made it possible to determine the latency and temporal structure of the activation at a temporal scale of few hundreds of milliseconds. Despite the sluggishness of the hemodynamic response, fMRI can detect a cascade of neural activations - the signature of a sequence of cognitive processes. Decomposing the processing into stages is greatly aided by measuring intermediate responses. By combining event-related fMRI and behavioral measurement in experiment and analysis, trial-by-trial temporal links can be established between cognition and its neural substrate.

\section{Addresses}

Department of Cognitive Neuroscience, Faculty of Psychology, Maastricht University, Postbus 616, 6200 MD Maastricht, The Netherlands

*e-mail: e.formisano@psychology.unimaas.nl

†e-mail: r.goebel@psychology.unimaas.nl

\section{Current Opinion in Neurobiology 2003, 13:174-181}

This review comes from a themed issue on Cognitive neuroscience

Edited by Brian Wandell and Anthony Movshon

0959-4388/03/\$ - see front matter

(c) 2003 Elsevier Science Ltd. All rights reserved.

DOI 10.1016/S0959-4388(03)00044-8

$\begin{array}{ll}\text { Abbreviations } \\ \text { BOLD } & \text { blood-oxygenation-level-dependent } \\ \text { EEG } & \text { electroencephalography } \\ \text { fMRI } & \text { functional MRI } \\ \text { HR } & \text { hemodynamic response } \\ \text { ICA } & \text { independent component analysis } \\ \text { M1 } & \text { primary motor area } \\ \text { MEG } & \text { magnetoencephalography } \\ \text { PPC } & \text { posterior parietal cortex } \\ \text { RT } & \text { reaction time } \\ \text { rTMS } & \text { repetitive transcranial magnetic stimulation } \\ \text { SMA } & \text { supplementary motor area } \\ \text { V1 } & \text { primary visual cortex }\end{array}$

\section{Introduction}

Mental chronometry is the attempt to decompose a perceptual, cognitive or motor task into a sequence of processing stages on the basis of measured response times $[1,2]$. Initially, mental chronometric studies were based exclusively on analyzing the behavioral response time or 'reaction time' (RT) as a function of the task condition
[1-4]. More recently, behavioral R'T information has been complemented with invasive $[5,6]$ and non-invasive [4,7-9] measurements of brain activity.

Electroencephalography (EEG) and magnetoencephalography (MEG) have been used widely in humans and seem to be particularly suited for relating sequences of neural events to sequences of cognitive stages that underlie the execution of a task. Indeed, EEG and MEG recordings of event-related responses reflect changes in neuronal activity on a timescale of milliseconds. Owing to intrinsic limitations, however, these methods can provide only relatively poor information about the spatial layout of the neural activity. By contrast, blood-oxygenation-leveldependent (BOLD) functional magnetic resonance imaging (fMRI), provides finer spatial resolution but, conventionally, poor temporal resolution.

In the present review, we discuss the possibility of using event-related fMRI $[10,11]$ to trace not only the topography but also the sequence of cortical activation across brain regions during perceptual or cognitive tasks. Recent results $[12,13]$ show that 'slow' fMRI can trace sequences of neural events surprisingly well and that the achieved temporal resolution ( $\sim 100-200$ milliseconds $)$ is sufficient to serve as an important guide in many mental chronometric measurements. When such a temporal resolution is acceptable, using fMRI alone to gain information about time and space simultaneously has several practical advantages over integrating fMRI with EEG/MEG measurements. This latter approach is the most promising for mapping the cortical activation that underlies a cognitive task with high spatial and temporal detail [14]; however, many unresolved theoretical (e.g. matching signals whose neuronal basis differ), methodological and technical issues still prevent its optimal application.

This is particularly true for complex cognitive tasks that involve distributed networks with many activated brain regions. First, when brain activation is expected to be largely distributed, it is more difficult to derive from a field distribution recorded on the scalp an accurate model of brain activity in terms of electric or magnetic sources [14]. Second, EEG and MEG measurements are not very sensitive for long-lasting, sustained processes and are better suited to detect effects that are closely time-locked to external stimulus-onsets. Spatially and temporally resolved measurements may be possible in the future by direct magnetic resonance mapping of neural magnetic fields; however, this attractive alternative is still in its infancy [15]. 
fMRI-based mental chronometry relies on the assumption that temporal sequences of spatially localized neural events are reflected in sequences of spatially localized BOLD responses (which in the following are referred to as hemodynamic responses or HRs) [12,13]. These spatiotemporal patterns of hemodynamic activation are detected using acquisition and analysis tools that preserve the temporal structure of the data ('time-resolved fMRI'). As in mental chronometric studies conducted with EEG/MEG, estimated spatio-temporal patterns of HRs can be linked to the subject's percept and/or behavioral response, and used to interpret or refine neurophysiologically plausible cognitive models.

\section{Mental chronometry using time- resolved fMRI Physiological assumptions}

The basic assumption in fMRI-based mental chronometry is that timing differences in observed HRs are attributable to the underlying neural events. Assessing the degree to which this assumption holds, however, is not simple. Despite recent improvements in our understanding of the nature of the link between the hemodynamic and neural domains [16-18], it remains unclear what and how much of the 'neural code' is reflected in the sluggish and spatially averaged BOLD response [19]. Many nonneuronal biophysical factors might differentially affect latency and other parameters of evoked HRs in the different brain areas, thus confounding a neural interpretation of fMRI observations. Among these factors, the variability of the characteristics of neurovascular coupling across brain areas seems to be the most relevant [20,21]

To delineate the possibilities and limitations of fMRIbased mental chronometry, further basic research with combined fMRI and electrophysiology in animals $[16,17]$ and investigation of the microstructure of the neurovascular system in different brain areas [22] are mandatory. Promisingly, preliminary results from combined fMRI and electrophysiology in monkeys suggest that temporal dependencies between brain areas observed during spontaneous activity in the neuronal local field potentials are reflected in the measured BOLD responses (AD Leopold, MA Augath, NK Logothetis, programme 325.7 in Soc Neurosci Abstr 2002).

\section{What is resolved in time-resolved fMRI?}

In their seminal work, Menon et al. [12] collected rapid fMRI images in restricted brain areas and examined the onset latency of the BOLD responses to single trials of two simple tasks. The first task involved a hemifield checkerboard presentation in which stimulation of the right hemifield followed $0,125,250,500$ or $1000 \mathrm{~ms}$ after stimulation of the left hemifield. Despite a relatively large intersubject variability in the absolute latency of HRs to visual stimuli, the latency difference between the BOLD responses of right and left primary visual cortex (V1) corresponded very well to the delay in stimulus presentation.

The second task was a cued visuo-motor RT task that allowed the sequence of brain activation to be traced from V1 to the supplementary motor area (SMA) and to the primary motor area (M1). Results from this experiment indicated that sequential spatially localized neural events are reflected in sequential spatially localized HRs in a more complex task. These results also indicated, however, that caution should be taken in interpreting absolute differences in HR latencies. Importantly, the latency difference between V1 and SMA, but not that between SMA and M1, was correlated to the subject's RT (see also [23]).

Notwithstanding remaining physiological uncertainties, the results of Menon et al. [12], together with the experimental evidence that has been gathered so far [12, $\left.23-28,29^{\bullet}, 30,31^{\bullet \bullet}, 32\right]$, support the idea that mental chronometric studies can be carried out with time-resolved fMRI. The achievable temporal resolution is in the order

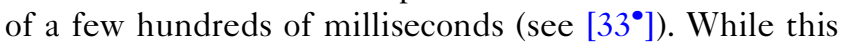
temporal scale is too slow to detect fast interactions that occur continuously between connected brain areas, it seems to be sufficient to resolve the flow of information in cortical networks at a timescale relevant for various perceptual and cognitive tasks.

Although brain areas may process information in parallel, many complex cognitive tasks contain serial stages of processing, with specific stages producing intermediate outputs that are required for initiating subsequent processing stages [4]. If, for example, an area A needs $100 \mathrm{~ms}$ to compute a representation that is required as input for an area $\mathrm{B}$, then a 'cognitive' temporal order is imposed on these areas in the 100-ms range (Figure 1). At the neuronal level, areas A and B might exchange some information continuously during these $100 \mathrm{~ms}$, but only if area A has generated an adequate representation for area B can area B start to process the input and compute another representation that might be adequate to initiate downstream processing in other brain areas. The increased processing in many neurons of area $\mathrm{B}$ is expected to be accompanied by a rise in pooled activity that is strong enough to be measurable with BOLD fMRI. In contrast, activity in area $\mathrm{A}$ is expected to decrease if no further input needs to be processed. The exact temporal order of successively activated brain areas depends on the subprocesses involved in a task and on the amount of time that the involved brain areas need to compute representations that are adequate input for other brain areas.

Differences in the onset of activation of an area in different tasks can be measured accurately with timeresolved fMRI (within a subject, the HR of a region is indeed highly reproducible [20]). Additional caution 
Figure 1

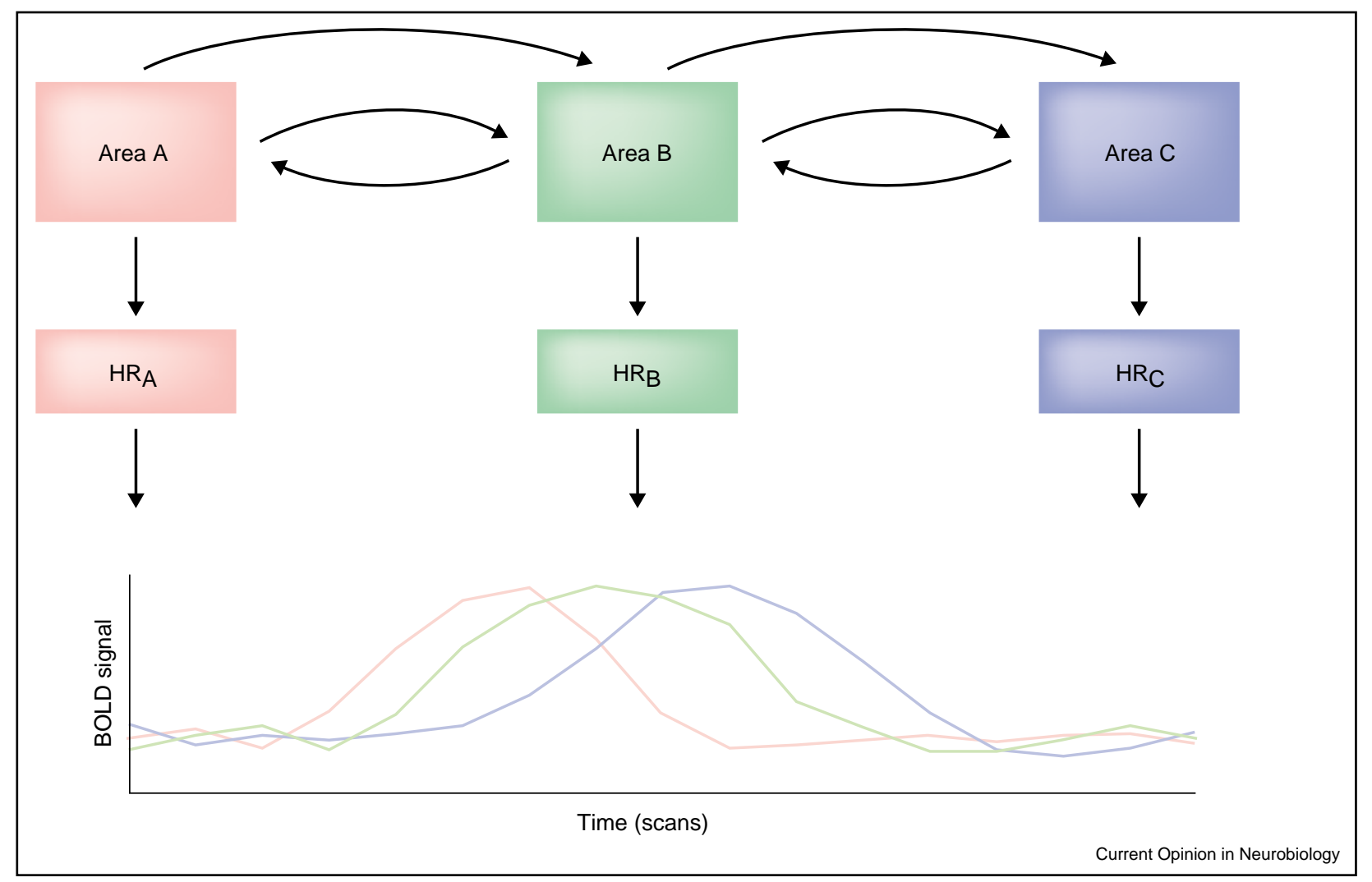

Time-resolved fMRI. In time-resolved fMRI, information on the relative onset times of brain areas is based on measuring the onset latency of the sluggish HRs of those areas and not directly on the onset of neural events. This indirect nature of the method and the intrinsic variability of the HRs across brain areas both limit the achievable temporal resolution to a few hundreds of milliseconds. Although this temporal scale cannot detect fast interactions that occur continuously between connected brain areas (small arrows), it seems to be sufficient to resolve the flow of information in cortical networks at a timescale relevant for various perceptual and cognitive tasks (large arrows).

should be taken in interpreting onset differences across different brain regions. If the estimated difference between the HR onset latencies in two brain areas is large (in the order of a second), it is likely that it reflects the true neuronal order (within a subject the variability of the HR latency across brain areas seems to be in the order of hundreds of milliseconds [34]). Conversely, smaller HR onset asynchronies (in the order of $100 \mathrm{~ms}$ or less) might be confounded by systematic neurovascular differences between brain areas.

The interpretability of relative timing differences between arbitrary brain areas can be tested by using several tasks that exert a differential influence on temporal activation or that require execution of the same subprocesses but in a different temporal order [29 $9^{\circ}$. These approaches presuppose sufficient knowledge about the subcomponents involved in the selected tasks.

Behavioral measurements, especially RT data, represent an important source of information that can reveal the neural origin of HR onset latencies. Indeed, when looking at the dependence of onset latency and other parameters of the HRs on the RT on a trial-by-trial basis, any observed systematic timing effect within an area must be attributable to neuronal dynamics because the biophysical parameters do not change $\left[28,31^{\bullet \bullet}\right]$.

\section{Optimizing the functional measurement}

From a methodological perspective, the possibility of carrying out mental chronometric studies using fMRI depends crucially on the capability of obtaining a precise measurement of the delay (and other temporal properties) of the HR in different regions of the brain.

As in acquisition of the functional images, one should consider that a fast temporal sampling of the HRs will lead to a better estimate of their temporal properties. In standard echo-planar imaging, temporal sampling of the fMRI responses is determined by the volume repetition time, which in turn depends on the number of collected slices and on the desired matrix dimensions. If testing specific hypotheses, one can increase temporal sampling by collecting images from limited regions of the brain. 
Complex cognitive tasks, however, usually activate spatially remote regions of the brain, thus requiring the collection of several slices.

In practice, the compromise between spatial and temporal measurement requirements leads to repetition times of $1-2 \mathrm{~s}$, which have been shown to be adequate for mapping specific sequences of cognitive stages. Higher magnetic fields [35] and/or parallel imaging with phased array coils [36] allow, for a given spatial resolution, higher temporal sampling rates. The sampling rate of HR can be also increased using an acquisition scheme that combines data collected in separate runs that differ in when the stimulus occurs in relation to the image acquisition (e.g. see [26,37]). This latter approach requires, however, additional assumptions in the analysis of the HRs and cannot be used for a true single-trial analysis.

\section{Optimizing the statistical analysis}

How can the delay of the HR be estimated from an fMRI time course? As in the preprocessing of time series, special caution should be taken in all those steps that may affect the temporal properties of the HRs. Specifically, because tracing the sequence of regional activations requires a comparison of time series obtained from different slices collected at different times, the temporal realignment of the slices (the 'interslice time correction' [38]) assumes a particular relevance. To preserve as much information as possible on dynamic aspects of the HRs (e.g. onset from baseline and rising edges of the BOLD response), temporal filtering of the time courses should be limited to removing linear and non-linear drifts.

Several methods have been proposed for estimating the latency and other parameters of the HRs $\left[21,31^{\bullet \bullet}, 32,37\right.$, $39-44,45^{\circ}$ ]. Representations of the spatial distribution of latencies across brain regions can be obtained by mapping the lag, yielding maximum cross-correlation between lagged HR models and fMRI data [21] or, in the case of periodic stimulation, the phase of the Fourier transform of the time series. Within the context of the general linear model, latency maps can be obtained by including in the design matrix of the experiment not only a model of the expected response but also either its temporal derivative [39] or shifted models of the expected response [31 $\left.{ }^{\bullet \bullet}\right]$.

Two approaches have been proposed recently that provide general and robust statistical methods for estimating and making inferences about latencies of the HR $\left[32,45^{\circ}\right]$. Both methods allow an accurate estimate of the latency and of its standard error. Other proposed approaches rely on non-linear, iterative fitting procedures of the HRs $[28,37,43,44]$. These latter methods allow a larger number of free parameters to be used in estimating the shape of HR and thus can better capture the intrinsic variability of the HRs in different regions of the brain or in different subjects. However, they are computationally more inten- sive and, in noisy time series, the estimation algorithm might not converge. Although these methods also can be used to obtain latency maps, they are normally used for a detailed post hoc analysis of HRs in preselected regions of interest $\left[28,31^{\bullet \bullet}\right]$.

All methods mentioned so far rely on fixed, predefined models of the HR. The precise shape of the BOLD impulse response for a given region is usually unknown, however, and, as discussed above, a certain degree of variability between regions - due to both neural and hemodynamic factors - should be expected. As a consequence, assuming a given model in the analysis might result in a different sensitivity in one or another region of the brain, depending on how well the specified model represents the actual HR of each region.

A complementary approach for mapping the spatiotemporal pattern of brain activation is to use a multivariate, data-driven method such as spatial 'independent component analysis' (ICA) [46]. In spatial ICA, individual functional data sets are decomposed blindly into spatially independent maps, each with an associated time course. Because spatial ICA does not make assumptions about the time course of the HRs, this method has been used successfully to investigate the variability in single trials of the HRs [47] and to detect HRs with unexpected temporal profiles [48]. As described below, spatial ICA can also be used to obtain a description of the sequence of spatial patterns of brain activation in event-related and fMRI-based mental chronometric studies ([49 ${ }^{\circ}$; E Formisano, F Di Salle, R Goebel, programme 490.8 in Soc Neurosci Abstr 2000).

\section{Applications}

In the past few years, time-resolved fMRI has been used to investigate a range of functional domains. Thierry $e t a l$. [25] traced the sequence of brain activation from input language regions (auditory cortex and Wernicke's area) to regions involved in the articulatory loop (Broca's area) and to motor output regions (precentral gyrus) in a fast repetition and a phoneme monitoring task.

Richter et al. [24,28] used time-resolved fMRI at 4 Tesla to investigate activity in motor and premotor areas during a mental rotation task. They carried out a chronometric analysis in selected brain regions and correlated several parameters (e.g. onset latency and width) of the HRs with the subject's RT in single trials of the task. This type of analysis allows discrimination of the subset of activated brain regions (superior parietal lobule, lateral premotor area and SMA) that are involved directly in the mental rotation of the objects. Activation patterns related to target detection [50], movement preparation, intention and execution $\left[26,29^{\circ}, 51\right]$ and lexical decision making $\left[52^{\circ \bullet}\right.$ ] have also been investigated using timeresolved fMRI. 
Figure 2

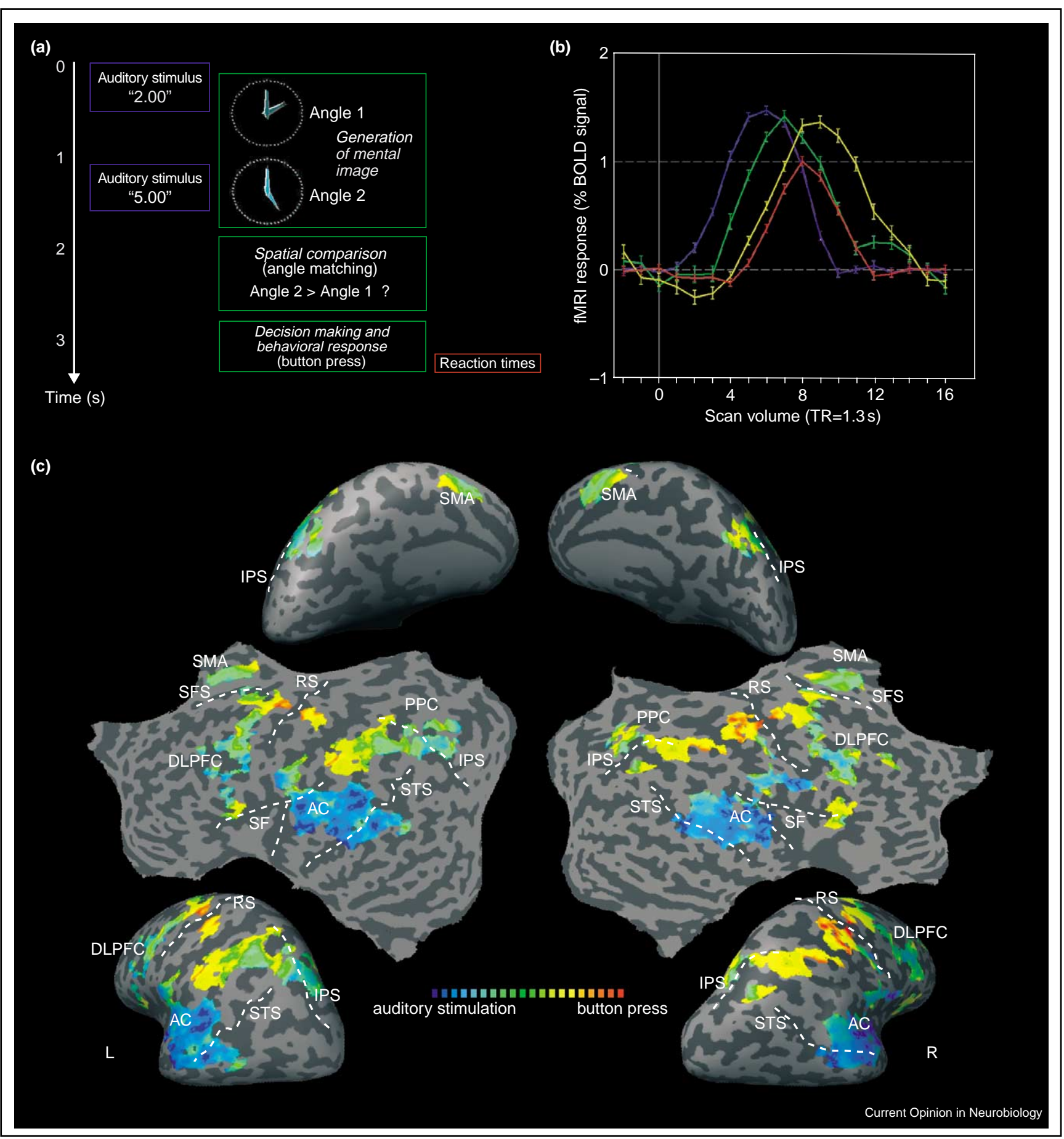

fMRI-based mental chronometry during visuo-spatial mental imagery: description of the 'mental clock task' [54] and hypothesis-driven analysis of functional time series. (a) During fMRI measurements, pairs of times are presented acoustically every $16 \mathrm{~s}$ (e.g. two o'clock and five o'clock). Subjects are instructed to imagine the corresponding analogue clock faces and push a button with their index finger if the hands of the first clock form the greater angle or another button with their middle finger if the hands of the second clock form the greater angle. A trial of the mental clock task thus involves auditory perception, translation of the auditory information into mental representations that explicate the angles, comparison of the angles and behavioral response. (b) Event-related BOLD responses of the auditory cortex (blue), left (green) and right (yellow) posterior parietal cortex and motor cortex (red) during a trial of the mental clock task [31 ${ }^{\circ \bullet}$. (c) Time-resolved multiple regression analysis of event-related fMRI time series. Multisubject $(n=6)$ general linear model surface maps are superimposed on an inflated and flattened representation of the cortical sheet of a template brain normalized in Talairach space. The color of significantly task-related voxels $(p<0.001$, corrected) encodes the relative latency of BOLD activation after auditory presentation of the stimulus. Blue and red indicate, respectively, early and late latencies of task-related activation 


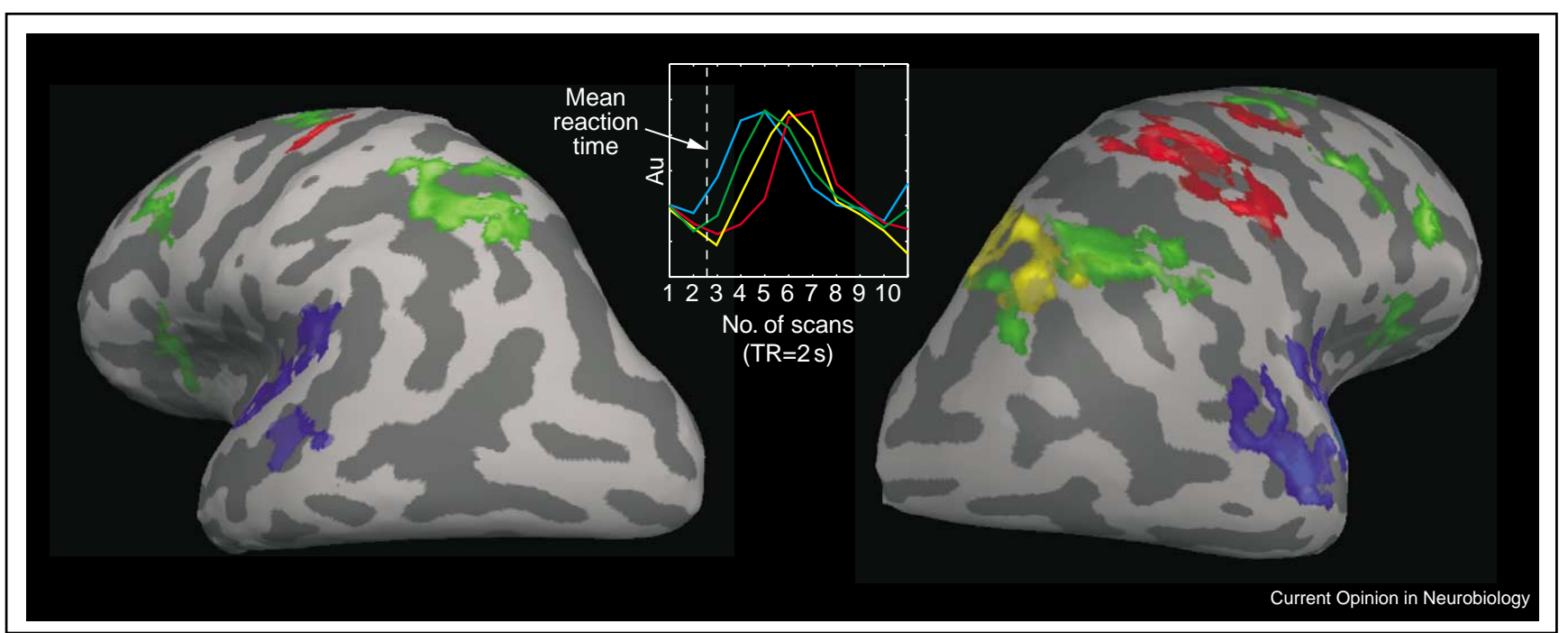

fMRI-based mental chronometry during visuo-spatial mental imagery: data-driven analysis of functional time-series. Individual surface components obtained with cortex-based ICA are projected on the inflated representation of the subject's cortex (caudomedial view). Different colors represent different components. Event-related averaged time courses of the components are shown in the inset. Note that that this type of data-driven analysis is useful not only to detect the temporal sequence of brain activation but also to highlight the simultaneous involvement of spatially remote regions in the same stage of the task. Brain regions that most probably are involved in the same stage of the task (bilateral auditory and language regions

[blue] in the early stages, and bilateral sensorimotor regions [red] in the late stages) are included in the same component. In agreement with the results from conventional analysis, the components corresponding to the fronto-parietal activation show very typical spatio-temporal features. The first component (green) has clusters located mainly, but not exclusively, in the left PPC. Additional clusters are also present in the right PPC and in the prefrontal cortex. The second component (yellow) is highly lateralized with clusters located almost exclusively in the right PPC on the superior part of the IPS. The time-courses of these two components show that the activation of the component lateralized in the right PPC followed the activation of the other, less-lateralized component. Abbreviation: $\mathrm{AU}$, arbitrary units.

\section{fMRI-based mental chronometry in visuo-spatial mental imagery}

Mental imagery refers to the generation and manipulation of mental representations in the absence of sensory stimulation. The sequences of processing stages that are required to generate and manipulate mental images have been investigated widely using classical RT-based mental chronometry methods $[3,53]$.

In a recent study, we and our co-workers [ $\left.31^{\bullet \bullet}\right]$ developed further the approach proposed by Menon and co-workers $[12,28]$ and used fMRI-based mental chronometry to address the issue of functional differentiation between the various cortical areas subserving the 'mental clock task' $[54,55]$ - a complex task of visuo-spatial mental imagery. In this mental imagery paradigm, subjects are asked to imagine pairs of clock faces on the basis of acoustically presented times, to compare the mental images and to report in which of the two faces the clock hands form the greater angle. The mental clock task requires several seconds of processing and thus is particularly well suited for an fMRI-based mental chronometry investigation (Figure 2a).

A time-resolved analysis of collected time series using conventional group and single-subject analysis detected a sequence of cortical activation from auditory perception to motor response with asymmetric (sequential) activation of the left and right posterior parietal cortex (PPC) (Figure 2b,c; $\left[31^{\bullet \bullet}\right]$ ). Whereas the left PPC was activated relatively early in the course of task performance, the main clusters of the right PPC became active significantly later. Part of the right PPC also participated in earlier activation, however, indicative of a transition from an early, more distributed, processing stage (presumably the construction of the mental representation of the angular information) to a later stage (presumably the spatial analysis) that is largely confined to the right PPC. Similar results were obtained when functional time-series were analyzed using cortex-based ICA, a

(Figure 2 Legend Continued) corresponding to the auditory stimulation and motor response. Intermediate latencies are represented linearly according to the color bar. Abbreviations: AC, auditory cortex; DLPFC, dorso-lateral prefrontal cortex; IPS, intraparietal sulcus; MC, motor cortex; PFC, prefrontal cortex; PPC, posterior parietal cortex; RS, rolandic sulcus; SF, Sylvian fissure; SFS, superior frontal sulcus; SMA, supplementary motor area; STS, superior temporal sulcus. Reprinted, with permission, from [31 ${ }^{\bullet \bullet}$ ]. 
data-driven method that combines spatial ICA with reconstructions of the cortex (Figure 3; [56]).

The hypothesis that early and late clusters in the PPC participate in different stages of the task was confirmed by a trial-by-trial analysis of correlations between RT and the onset latency, width and amplitude of the HRs in the activated brain regions [31 ${ }^{\bullet \bullet}$ ] and by a subsequent study using repetitive transcranial magnetic stimulation (rTMS) [57]. In this latter study, significantly slower R'Ts were observed when the right, but not the left, PPC was transiently suppressed by an rTMS coil. These results support the interpretation of a 'weak' left hemispheric specialization in the PPC for generating mental images and 'strong' right hemispheric specialization in the PPC for subsequent spatial analysis of these images.

\section{Conclusions}

Despite remaining physiological uncertainties, fMRIbased mental chronometry is a viable approach to detect information about the neural substrate of sequentially operating subcomponents in complex cognitive tasks. The achievable temporal resolution is in the order of a few hundred milliseconds. To investigate spatio-temporal brain processes with higher resolution, a combination of fMRI and EEG or MEG seems to be the most promising approach at present. Unfortunately, relating fMRI and EEG or MEG to each other in an integrated statistical model is very difficult. Time-resolved fMRI does not suffer from these problems and allows measurements of brain activity with good spatial and, for many questions, acceptable temporal resolution.

An important additional approach to mental chronometry seems to be the combination of time-resolved fMRI with stimulus time-locked single-pulse TMS [58]. The latter technique enables spatio-temporal hypotheses derived from fMRI-based mental chronometry studies to be tested directly by interrupting processing in specific brain regions at precise moments in time.

fMRI-based mental chronometry can provide a new type of information that goes beyond the identification of co-activated brain regions during a cognitive task. Using this approach, cognitive neuroscientists will be able to differentiate the contribution of activated regions to the specific processing stages required to perform a task and to link together cognition, behavior and brain activity.

\section{Acknowledgements}

We are grateful to Nikolaus Kriegeskorte and David EJ Linden for useful comments on the manuscript and to Alard Roebroeck for providing Figure 1.

\section{References and recommended reading}

Papers of particular interest, published within the annual period of review, have been highlighted as:
- of special interest

$\bullet$ of outstanding interest

1. Donders FC: On the speed of mental processes (translation). Acta Psychol (Amst) 1969, 30:412-431.

2. Sternberg S: The discovery of processing stages: extensions of Donder's method. Acta Psychol (Amst) 1969, 30:276-315.

3. Posner MI: Chronometric Explorations of Mind. New York: Oxford University Press; 1978.

4. Meyer DE, Osman AM, Irwin DE, Yantis S: Modern mental chronometry. Biol Psychol 1988, 26:3-67.

5. Georgopoulos AP, Pellizzer G: The mental and the neural: psychological and neural studies of mental rotation and memory scanning. Neuropsychologia 1995, 33:1531-1547.

6. Georgopoulos AP, Taira M, Lukashin A: Cognitive neurophysiology of the motor cortex. Science 1993, 260:47-52.

7. Renault B, Ragot R, Lesevre N, Remond A: Onset and offset of brain events as indices of mental chronometry. Science 1982 , 215:1413-1415.

8. Hillyard SA: Electrical and magnetic brain recordings: contributions to cognitive neuroscience. Curr Opin Neurobiol 1993, 3:217-224.

9. Hari R, Levanen S, Raij T: Timing of human cortical functions during cognition: role of MEG. Trends Cogn Sci 2000, 4:455-462.

10. Rosen BR, Buckner RL, Dale AM: Event-related functional MRI: past, present, and future. Proc Natl Acad Sci USA 1998, 95:773-780.

11. Buckner RL: Event-related $f M R I$ and the hemodynamic response. Hum Brain Mapp 1998, 6:373-377.

12. Menon RS, Luknowsky DC, Gati JS: Mental chronometry using latency-resolved functional MRI. Proc Natl Acad Sci USA 1998 , 95:10902-10907.

13. Menon RS, Kim SG: Spatial and temporal limits in cognitive neuroimaging with fMRI. Trends Cogn Sci 1999, 3:207-216.

14. Dale AM, Halgren E: Spatiotemporal mapping of brain activity by integration of multiple imaging modalities. Curr Opin Neurobiol 2001, 11:202-208.

15. Bodurka J, Bandettini PA: Toward direct mapping of neuronal activity: MRI detection of ultraweak, transient magnetic field changes. Magn Reson Med 2002, 47:1052-1058.

16. Logothetis NK, Pauls J, Augath M, Trinath T, Oeltermann A: Neurophysiological investigation of the basis of the fMR signal. Nature 2001, 412:150-157.

17. Logothetis NK: The neural basis of the blood-oxygen-leveldependent functional magnetic resonance imaging signal. Philos Trans R Soc Lond B Biol Sci 2002, 357:1003-1037.

18. Attwell $D$, ladecola $C$ : The neural basis of functional brain imaging signals. Trends Neurosci 2002, 25:621-625.

19. Zarahn $\mathrm{E}$ : Testing for neural responses during temporal components of trials with BOLD fMRI. Neurolmage 2000 , 11:783-796.

20. Aguirre GK, Zarahn E, D'Esposito M: The variability of human, BOLD hemodynamic responses. Neurolmage 1998, 8:360-369.

21. Saad ZS, Ropella KM, Cox RW, DeYoe EA: Analysis and use of FMRI response delays. Hum Brain Mapp 2001, 13:74-93.

22. Harrison RV, Harel N, Panesar J, Mount RJ: Blood capillary distribution correlates with hemodynamic-based functional imaging in cerebral cortex. Cereb Cortex 2002, 12:225-233.

23. Richter W, Andersen PM, Georgopoulos AP, Kim SG: Sequential activity in human motor areas during a delayed cued finger movement task studied by time-resolved fMRI. NeuroReport 1997, 8:1257-1261.

24. Richter W, Ugurbil K, Georgopoulos A, Kim SG: Time-resolved fMRI of mental rotation. NeuroReport 1997, 8:3697-3702. 
25. Thierry G, Boulanouar K, Kherif F, Ranjeva JP, Demonet JF: Temporal sorting of neural components underlying phonological processing. NeuroReport 1999, 10:2599-2603.

26. Toni I, Schluter ND, Josephs O, Friston K, Passingham RE: Signal-, set- and movement-related activity in the human brain: an event-related fMRI study. Cereb Cortex 1999, 9:35-49.

27. Huettel SA, McCarthy G: Evidence for a refractory period in the hemodynamic response to visual stimuli as measured by MRI. Neurolmage 2000, 11:547-553.

28. Richter W, Somoriai R, Summers R, Jarmasz M, Menon RS, Gati JS, Georgopoulos AP, Tegeler C, Ugurbil K, Kim SG: Motor area activity during mental rotation studied by time-resolved single-trial fMRI. J Cogn Neurosci 2000, 12:310-320.

29. Weilke F, Spiegel S, Boecker H, von Einsiedel HG, Conrad B,

- Schwaiger M, Erhard P: Time-resolved fMRI of activation patterns in M1 and SMA during complex voluntary movement. $J$ Neurophysiol 2001, 85:1858-1863.

The authors use two tasks that exert differential influence on tempora activation to ensure that the observed cascade of activation during complex movements is not the result of differences in the hemodynamic response function.

30. Toni I, Thoenissen D, Zilles K: Movement preparation and motor intention. Neurolmage 2001, 14:S110-117.

31. Formisano E, Linden DE, Di Salle F, Trojano L, Esposito F, Sack AT,

- Grossi D, Zanella FE, Goebel R: Tracking the mind's image in the brain: time-resolved fMRI during visuo-spatial mental imagery. Neuron 2002, 35:185-194

In this study, fMRI-based mental chronometry is used to address the issue of functional differentiation among the various cortical areas involved in a complex mental imagery task. Although the identified spatia pattern of brain activation is in agreement with previous knowledge [55] the time-resolved and trial-by-trial analyses of fMRI responses highligh different functional roles for regions in the left and right posterior parieta cortex. These results are confirmed by a related study in which fMRI and rTMS are combined [57]

32. Henson RN, Price CJ, Rugg MD, Turner R, Friston KJ: Detecting latency differences in event-related BOLD responses: application to words versus nonwords and initial versus repeated face presentations. Neurolmage 2002, 15:83-97.

33. Hernandez L, Badre D, Noll D, Jonides J: Temporal sensitivity of event-related fMRI. Neurolmage 2002, 17:1018-1026.

This study reports a quantitative analysis of the temporal sensitivity that can be achieved in event-related fMRI. Using computer simulations and real data the authors conclude that temporal resolution of $\mathrm{AMRI}$ is in the order of a few hundred milliseconds with $95 \%$ confidence.

34. Huettel SA, McCarthy G: Regional differences in the refractory period of the hemodynamic response: an event-related fMRI study. Neurolmage 2001, 14:967-976.

35. Pfeuffer J, Van de Moortele PF, Yacoub E, Shmuel A, Adriany G, Andersen P, Merckle H, Garwood M, Ugurbil K, Hu X: Zoomed functional imaging in the human brain at 7 Tesla with simultaneous high spatial and high temporal resolution. Neurolmage 2002, 17:272-286.

36. Griswold MA, Jakob PM, Chen Q, Goldfarb JW, Manning WJ, Edelman RR, Sodickson DK: Resolution enhancement in single-shot imaging using simultaneous acquisition of spatial harmonics (SMASH). Magn Reson Med 1999, 41:1236-1245.

37. Miezin FM, Maccotta L, Ollinger JM, Petersen SE, Buckner RL: Characterizing the hemodynamic response: effects of presentation rate, sampling procedure, and the possibility of ordering brain activity based on relative timing. Neurolmage 2000, 11:735-759.

38. Van de Moortele PF, Cerf B, Lobel E, Paradis AL, Faurion A, Le Bihan D: Latencies in fMRI time-series: effect of slice acquisition order and perception. NMR Biomed 1997, 10:230-236.

39. Friston KJ, Fletcher P, Josephs O, Holmes A, Rugg MD, Turner R: Event-related fMRI: characterizing differential responses. Neurolmage 1998, 7:30-40.

40. Rajapakse JC, Kruggel F, Maisog JM, von Cramon DY: Modeling hemodynamic response for analysis of functional MRI time-series. Hum Brain Mapp 1998, 6:283-300.
41. Kruggel F, von Cramon DY: Modeling the hemodynamic response in single-trial functional MRI experiments. Magn Reson Med 1999, 42:787-797.

42. Kruggel F, von Cramon DY: Temporal properties of the hemodynamic response in functional MRI. Hum Brain Mapp 1999, 8:259-271.

43. Calhoun V, Adali T, Kraut M, Pearlson G: A weighted leastsquares algorithm for estimation and visualization of relative latencies in event-related functional MRI. Magn Reson Med 2000, 44:947-954.

44. Purdon PL, Solo V, Weisskoff RM, Brown EN: Locally regularized spatiotemporal modeling and model comparison for functional MRI. Neurolmage 2001, 14:912-923.

45. Liao CH, Worsley KJ, Poline JB, Aston JA, Duncan GH, Evans AC - Estimating the delay of the fMRI response. Neurolmage 2002, 16:593-606.

This paper discusses thoroughly problems related to the statistical estimation of the delay in the fMRI response. A fast, efficient and robust method is proposed and validated.

46. McKeown MJ, Makeig S, Brown GG, Jung TP, Kindermann SS, Bell AJ, Sejnowski TJ: Analysis of fMRI data by blind separation into independent spatial components. Hum Brain Mapp 1998, 6:160-188.

47. Duann JR, Jung TP, Kuo WJ, Yeh TC, Makeig S, Hsieh JC, Sejnowski TJ: Single-trial variability in event-related BOLD signals. Neurolmage 2002, 15:823-835.

48. Seifritz E, Esposito F, Hennel F, Mustovic H, Neuhoff JG, Bilecen D, Tedeschi G, Scheffler K, Di Salle F: Spatiotemporal pattern of neural processing in the human auditory cortex. Science 2002 297:1706-1708.

49. Calhoun VD, Adali T, McGinty VB, Pekar JJ, Watson TD, Pearlson

- GD: fMRI activation in a visual-perception task: network of areas detected using the general linear model and independent components analysis. Neurolmage 2001, 14:1080-1088.

This study shows the use of spatial ICA for detecting spatio-tempora patterns of brain activation in event-related fMRI studies.

50. Shulman GL, Ollinger JM, Linenweber M, Petersen SE, Corbetta M Multiple neural correlates of detection in the human brain Proc Natl Acad Sci USA 2001, 98:313-318.

51. Lee KM, Chang KH, Roh JK: Subregions within the supplementary motor area activated at different stages of movement preparation and execution. Neurolmage 1999, 9:117-123.

52. Bellogwan PSF, Saad ZS, Bandettini PA: Understanding neural

-. system dynamics through task modulation and measurement of functional MRI amplitude, latency and width. Proc Natl Acad Sci USA 2003, 100:1415-1419.

In this study, neural system dynamics that are involved in lexical decision making are investigated using fMRI-based mental chronometry. Bellogwan and co-workers show that the estimation of latency and width of HRs in combination with an appropriate modulation of a task can be used to differentiate between neural routes for the processing of words and nonwords.

53. Kosslyn SM: Image and Brain: the Resolution of the Imagery Debate. Cambridge, MA: MIT Press; 1994.

54. Paivio A: Comparisons of mental clocks. J Exp Psychol Hum Percept Perform 1978, 4:61-71.

55. Trojano L, Grossi D, Linden DE, Formisano E, Hacker H, Zanella FE, Goebel R, Di Salle F: Matching two imagined clocks: the functional anatomy of spatial analysis in the absence of visual stimulation. Cereb Cortex 2000, 10:473-481.

56. Kriegeskorte N, Goebel R: An efficient algorithm for topologically correct segmentation of the cortical sheet in anatomical MR volumes. Neurolmage 2001, 14:329-346.

57. Sack AT Sperling JM, Prvulovic D, Formisano E Goebel R, Di Salle F, Dierks T, Linden DE: Tracking the mind's image in the brain II: transcranial magnetic stimulation reveals parietal asymmetry in visuo-spatial imagery. Neuron 2002, 35:195-204.

58. Ganis G, Keenan JP, Kosslyn SM, Pascual-Leone A: Transcrania magnetic stimulation of primary motor cortex affects mental rotation. Cereb Cortex 2000, 10:175-180. 